\title{
A relação entre os elementos visuais da tribo Boruca com técnicas artesanais de Design de Superfície.
}

The relashion between Boruca's tribe visuals elements and Surface Design artisanal techniques.

FLORES NUNES, Gabriela; Bacharel; Universidade Feevale.

gabrielafloresnunes@gmail.com

STEIGLEDER, Ana Paula; Mestre; Universidade Feevale.

anapaulas@feevale.br

\section{Resumo:}

O presente trabalho apresenta o desenvolvimento de estampas artesanais aplicadas a uma coleção de moda conceitual inspirada na tribo indígena Boruca, localizada na Costa Rica. O trabalho relaciona elementos visuais da tribo através de técnicas artesanais de design de superfície. Para tanto, a questão que norteou esta pesquisa foi "a tribo Boruca como forma de inspiração para o desenvolvimento de uma coleção de moda e tratamento manual de superfície", onde técnicas de carimbo, tingimento e bordado foram exploradas. A pesquisa utiliza bibliografia como também conteúdo publicado na internet como apoio para criação. $O$ trabalho se dá em torno do estudo da cultura e artesanato Boruca, contextualizando o design de superfície e técnicas manuais do mesmo. $O$ design de superfície têxtil explorado de forma manual através de carimbos de elementos naturais, o tingimento natural e o bordado à mão inspirados nos elementos visuais dos Borucas, gerou um resultado exclusivo às peças desenvolvidas.

Palavras Chave: design de superfície; técnicas artesanais; boruca e coleção de moda.

\begin{abstract}
This article presents the artisanal prints development applied to conceptual fashion collection inspired by Boruca's tribe, located in Costa Rica. The document relates boruca's visuals elements with surface design artisanal techniques. Therefore, the question that guided this research was " the boruca's tribe as a way of inspiration for fashion collection and handcrafted surface development", where stamping, embroidery and dyeing were explore. The research happens around the Boruca's culture and craft study, contextualizing the surface design and artisanal techniques from the same. The textile surface design handmade explorated by natural stamp, natural dyeing and handmade embroidery that was inspirited on Boruca's visuals elements, created a exclusive result for the garment development.
\end{abstract}

Keywords: Surface design; artisanal techniques; boruca and fashion collection. 


\section{INTRODUÇÃO}

A presente pesquisa relaciona-se ao estudo dos elementos visuais da tribo Boruca da Costa Rica com técnicas artesanais de tratamento de superfície têxtil para aplicação em uma coleção de moda. O estudo mostra como o design de superfície e suas distintas técnicas artesanais podem gerar um resultado de grande valor e originalidade as peças criadas, como também uma relação de proximidade junto a tribo.

O design de superfície, conforme Rubim (2013), refere-se a todo projeto, o qual aborda o tratamento e cor aplicado a uma superfície industrial ou não. É necessário o entendimento da superfície como delimitadora da forma (RUTHSCHILLING, 2008). Todavia, segundo Freitas (2011), o DS tem como objetivo trabalhar a superfície, entendendo a mesma não apenas como material de proteção e acabamento, mas o que agrega carga comunicativa tanto com o ambiente externo ao objeto, quanto interno, transmitindo mensagens por meio dos sentidos, como cores, texturas e grafismos. A superfície deve ter relação com o homem e o ambiente interativamente em todos os sentidos, com seu público, local em que se encontra e com seu próprio volume. Percebe-se a importância da conexão que a superfície deve possuir com o meio externo e os elementos que o compõe, visando aspectos estéticos, funcionais e técnicos.

A tribo Boruca, é natural da Costa Rica e baseia-se nas crenças e no conhecimento de seus ancestrais possuindo um enorme respeito por sua cultura e pela natureza que os cercam. Os Borucas são a maior tribo do país e apesar de sofrerem grande interferência espanhola, os mesmos ainda mantém sua essência através de cerimônias como o baile de los diablitos e do seu artesanato local, como as suas máscaras, que traduzem fortemente a identidade da tribo e são fonte de inspiração para o desenvolvimento desta pesquisa, o qual serviram de inspiração para aplicação das técnicas manuais de design de superfície tais como os carimbos de elementos naturais, o tingimento natural e o bordado à mão.

\section{BORUCAS}

De acordo com Pérez (2007), as comunidades indígenas da Costa Rica ocupam cerca de trezentos e vinte mil hectares dentro do país, possuem uma população total de vinte e cinco mil pessoas e se dividem entre oito tribos: os cabecares, bribris, guaymies, terrabas, malekus, huetares, chorotegas e os borucas, tribo indígena foco desta pesquisa.

A população Boruca é formada por duas mil pessoas, portanto somente mil e setecentos vivem na comunidade e o restante se considera parte da etnia Boruca. A região é formada por uma área de aproximadamente cento e quarenta kilômetros quadrados. De acordo com Pacheco (1996), os Borucas vivem na província de Puntarenas, no sul do país e possuem características semelhantes a população rural da Costa Rica. Percebe-se a valorização da própria cultura através das gerações, enfatizando a importância dos seus ancestrais e de suas histórias. Em relação à identidade da tribo, o Boruca $^{1}$ afirma:

O povo Boruca é construído sobre a fé na sabedoria dos seus anciãos através das lendas que eles contam, transmitidas por séculos. A identidade Boruca reflete um profundo respeito pelas histórias contadas, pela a natureza que os cercam e pela comunidade que compartilham (BORUCA, 2017, tradução nossa).

\footnotetext{
${ }^{1}$ Acesso em: < http://www.boruca.org/en/about-boruca/
} 
De acordo com Boruca (2017), a tribo vive em uma comunidade de agricultura sustentável, onde as famílias plantam arroz, feijão, cacau, frutas, milho e tomates. Eles também criam gado, frango e porco. Arroz e feijão são essenciais para qualquer refeição na comunidade dos borucas. Tortilhas de milho são incluídas muitas vezes nas refeições, enquanto a banana é uma adição para o café da manhã ou sobremesa.

\subsection{ARTESANATO BORUCA}

O artesanato Boruca é fonte de sustento para algumas famílias devido a sua originalidade, pois segundo eles vendem o artesanato para lojas locais e até mesmo enviam seus produtos para outros lugares da Costa Rica (BORUCA, 2017).

O baile de los diablitos segundo Pérez (2007) é uma representação em forma de drama que busca retratar a luta dos indígenas contra os colonizadores espanhóis, além de simbolizar o esforço dos indígenas para manterem suas tradições, costumes, crenças e idiomas. A cerimônia inicia-se em um lugar sagrado, onde os Borucas se comunicam com seus ancestrais e recebem energia para começar o ritual (CHAVES e INCERA, 2015). Segundo os autores, os borucas utilizam máscaras que os transformam em verdadeiros animais selvagens, as quais são esculpidas e pintadas à mão por eles mesmos. O baile de los diablitos é a atividade cultural de maior participação entre os membros Boruca e de outras comunidades indígenas como bribris, cabécares e terrábas. A economia local se reativa mais do que nunca nesta época, utilizando a matéria prima que provém da natureza: algodão, madeira e troncos, assim como a diversidade de folhas e caules que eles usam para extrair corantes. Tudo isso é transformado em máscaras, tecidos, enfeites de decoração e instrumentos musicais.

Para entender o artesanato Boruca, é necessária a compreensão sobre o artesanato como um todo. $\mathrm{O}$ artesanato é um objeto que expressa fortemente uma cultura, capaz de traduzir uma identidade, seja este produzido de forma individual ou coletiva, trazendo originalidade e exclusividade a um produto. $O$ artesanato não é uma simples mercadoria, ele remete também valores e crenças (LIMA, 2005), ou seja, o artesanato expressa em produtos feitos de forma majoritariamente manual, exclusiva e pitoresca que representa vigorosamente uma determinada cultura.

Segundo Boruca (2017), existem três segmentos de artesanato produzidos pelas tribos: a tecelagem ${ }^{2}$, os tambores e as máscaras. A tecelagem é ensinada para as mulheres desde a infância, porém, os homens também são ensinados a tecer. $O$ algodão utilizado para produzir o fio é cultivado localmente, depois passa pelo processo de torção, para em seguida, ser tecido no tear manual. Em relação ao tingimento, os indígenas possuem uma forte tradição com os pigmentos, que são de fontes naturais locais, como cascas de árvores, folhas e diferentes plantas. Os tecidos tingidos são transformados em bolsas, tapetes, sacos, entre outros. Os tambores produzidos pelos indígenas são cilindros feitos de cedro ${ }^{3}$ oco ou tronco de balsa ${ }^{4}$ envolto com couro de vaca.

\footnotetext{
${ }^{2}$ Tecelagem: é o ato de tecer, através do entrelaçamento de fios de trama (transversais) com fios de teia (português europeu) ou urdume (português brasileiro) (longitudinais), formando tecidos.

${ }^{3}$ Cedro: Nome comum de árvores das famílias das pináceas e das meliáceas que fornecem madeira leve, aromática e de cor marrom.

4 Árvore sul-americana, da família das Bombáceas, pode atingir cerca de trinta metros de
} 
Todavia, as máscaras desenvolvidas pela tribo referem-se ao artesanato mais conhecido dos Borucas. Para eles é um objeto cerimonial de extrema importância utilizado na cerimônia baile de los diablitos. Segundo Chang,

A máscara é um objeto cerimonial que o ser humano utiliza para ser identificado com seres naturais (humanos ou animais) ou sobrenaturais. Pode cumprir diversas funções sociais [...] a máscara tem sido utilizada respectivamente, como meio de transgressão da ordem estabelecida [...] (2007, p.69 apud CHAVES e INCERA, 2015, p.18-19).

O cacique da tribo complementa com sua fala no vídeo feito por Luan", ao dizer que "as máscaras escondem a timidez do jogador, além de trazer orgulho para o mesmo, pois é uma obra artística produzida por ele mesmo". A essência do artesanato ao trabalho manual é percebida de forma demasiada nas máscaras desenvolvidas pela tribo, uma vez que, segundo Boruca (2017), as máscaras são esculpidas na madeira de balsa e pintadas á mão através de uma técnica transmitida por gerações.

Conforme Boruca (2017) existem dois tipos de máscaras: as tradicionais e as ecológicas. As tradicionais, conforme Figura 01 (A), são o centro das atenções do juego de los diablitos e retratam os rostos "assustadores" da tribo indígena, como eram vistos através dos olhos dos espanhóis. Estas máscaras são feitas para parecerem "sinistras" e "assustadoras". Já as máscaras ecológicas ou culturais, conforme Figura 01 (B), trazem representações mais artísticas da cultura da tribo. Embora menos tradicionais, estas são cada vez mais populares entre os turistas que frequentam a região, pela representação da natureza e por sua beleza.

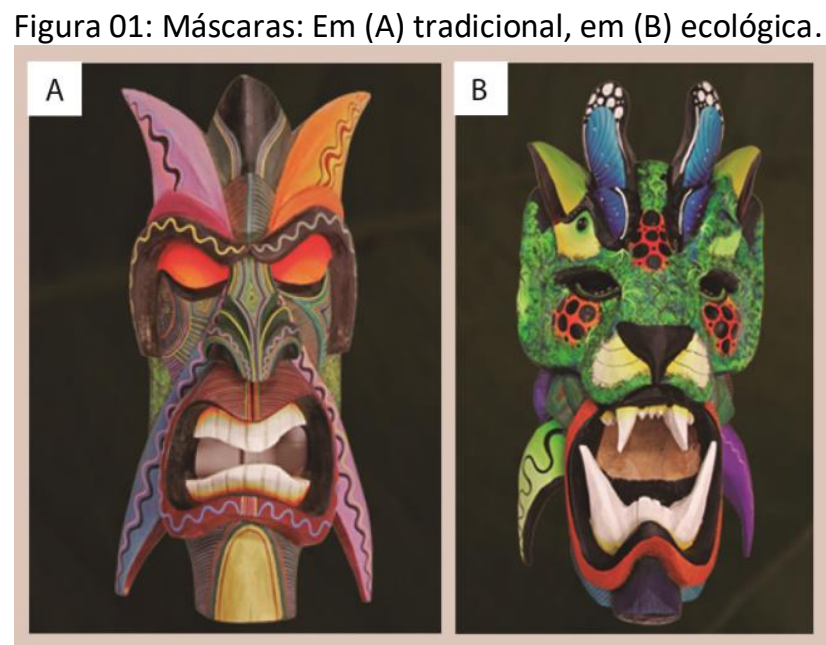

Fonte: BORUCA ${ }^{6}$

Analisando as máscaras ecológicas percebe-se a representação de diversos elementos naturais. Uma destas representações está presente na maior parte das cores utilizadas nas máscaras. As cores são definidas por Goode (2013), como "naturais": aquelas que evocam características da natureza (céu, terra, água, por exemplo). Outra representação da natureza que pode ser percebida é a reprodução de alguns animais como o tucano e a borboleta. A borboleta,

altura,tem folhas grandes e flores brancas e produz madeira muito leve e macia, usada usada na fabricação de barcos, maquetes, brinquedos, etc.

${ }^{5}$ Luan Schenkel: Voluntário que trabalhou em um projeto diretamente com os borucas através da AISEC (Associação Internacional de Estudantes de Economia e Ciências Comerciais).

${ }^{6}$ Acesso em < http://www.boruca.org/en/crafts/masks/>. 
segundo Gabriel7 , é um grande símbolo da natureza da região.

\section{DESIGN DE SUPERFÍCIE}

No Brasil o termo "design de superfície" ou "surface design", como é conhecido nos Estados Unidos, foi implementado pela autora e designer Renata Rubim. Para Ruthschilling (2008), a origem da expressão do design de superfície restringia-se apenas ao design têxtil, porém no Brasil, utiliza-se esta terminologia para especificar projetos de design para superfície de uma maneira mais ampla. Segundo Goode (2013), abrange moda, design de interiores, design gráfico, além de arte têxtil e artesanato.

A origem da estamparia é tão antiga quanto à existência das vestimentas. Desde o homo sapiens, havia esta arte. O início se deu através da técnica de estampar o próprio corpo e logo, as vestimentas, que eram necessárias para cobrir o corpo devido à temperatura. O primeiro instrumento para estampar tecidos foi a própria mão, depois pedaços de madeira começaram a permitir novas formas e desenhos variados (BUENO, 2013).

É importante destacar que as estampas projetadas possuem ou devem possuir uma relação forte com o design do produto ou da peça de vestuário (GOODE, 2013). Entende-se que ao projetar uma estampa localizada para uma determinada peça, é necessário primeiramente compreender o produto que a mesma será aplicada. Entender a textura do material que será trabalhado é fundamental no design de superfície. Freitas comenta que: "A percepção tátil é capaz de formar mapas de imagens sensoriais que, por sua vez, geram qualitativos, denominados descritores" (2010, p. 51). Ao tratar de textura, Wong (2010 apud TEIXEIRA, 2013), afirma que esta pode ser suave ou áspera, lisa ou decorada, fosca ou polida, macia ou dura e expõe dois grupos: textura visual e textura tátil. $O$ autor ainda comenta que a textura visual se resume em bidimensional, ou seja, percebida através do olhar, porém, provocando sensações táteis. Já a textura tátil, além de ser percebida pelo olhar, é sentida através das mãos, do tato, enfatizando sua característica tridimensional.

Acredita-se que o substrato o qual o designer pretende trabalhar deve ser estudado para se obter um bom resultado de um projeto que envolva design superfície. Como mencionado anteriormente, neste trabalho busca-se relacionar o design de superfície com os elementos visuais da tribo Boruca, e que estes sirvam de inspiração para aplicação de técnicas manuais tais como, o tingimento natural, carimbo de elementos naturais e o bordado à mão para produção de estampas.

\section{RESULTADOS}

\subsection{Tratamento artesanal de superfície: Tingimento Natural}

A relação do homem com o corante data cerca de quarenta mil anos, quando os pigmentos eram misturados com gordura animal e utilizados em pinturas rupestres. No Egito, foram encontrados tecidos tingidos com índigo azul. Já a Índia, em 2.500 a.C., possuía o domínio da

\footnotetext{
7 Gabriel: Voluntário que trabalhou em um projeto diretamente com os borucas através da AISEC (Associação Internacional de Estudantes de Economia e Ciências Comerciais).
} 
tinturaria e estamparia (FERREIRA, NOGUEIRA e GRACIANE, 2013). O tingimento natural produz originalidade aos tecidos, além de ser um acontecimento mágico ver a cor surgir através da extração do corante (ETNOBOTÂNICA, 2017). Os corantes sintéticos possuem uma pigmentação de excelente qualidade e fixação e devido à industrialização, estes corantes substituíram os corantes naturais. Porém, conforme Fletcher e Grose:

Nos processos de tingimento industriais é a natureza que fornece seus "recursos" para abastecerem as tecelagens, como por exemplo, no mundo todo estima-se que a indústria têxtil usa 378 bilhões de litros de água por ano (2011, p.37).

Percebe-se a relevante poluição dos corantes químicos no meio ambiente. Ademais, os processos de tingimento natural requerem uma abordagem mais artesanal e conectam o ser humano com a natureza. Com base nas pesquisas realizadas sobre a tribo Boruca e os processos manuais utilizados em seu artesanato, como por exemplo, o tingimento natural, observou-se a relevância de abordar este processo na coleção de moda. Visto que a tribo utiliza o tingimento natural em seu artesanato, desta forma, escolheu-se explorar o pigmento da cúrcuma, planta que entrega uma cor amarelada e é utilizada tanto no tempero de alimentos, como em cosméticos e medicamentos ${ }^{8}$.

Após os primeiros tingimentos, notou-se que a cor gerada pelo pigmento poderia ter tonalidades mais claras ou mais escuras, dependendo da concentração de pigmento na água. 0 objetivo para esse projeto, foi atingir o amarelo de tonalidade mais escura. Durante a pesquisa de processos, percebeu-se um fator importante, a necessidade de utilizar apenas tecidos de fibras naturais, como a seda, o algodão, o linho, etc. Outro aspecto importante foi aplicar um fixador, como por exemplo, o sal.

Para realizar o processo, utilizou-se sarja de algodão orgânico e após diversas análises referentes a ensaios realizados de tingimentos, encontrou-se a receita ideal. Foram necessários, 7 litros de água, 3 pacotes e $1 / 2$ de açafrão da terra (cúrcuma), 1 colher de pau, 1 coador de pano ou papel, 1 panela de 10 litros, 1 colher de sopa de sal branco fino e 1 concha.

O processo iniciou com a fervura da água com o sal, durante um período de dez minutos. Adicionou-se o corante e ferveu-se por mais vinte minutos. Logo, o tecido foi coado, separando os resíduos em pó da cúrcuma do líquido colorido. O próximo passo, foi lavar a panela e despejar apenas o líquido novamente na mesma, e após, colocar uma quantidade de tecido que ficasse coberta pelo líquido e fervesse para gerar uma cor uniforme. Para finalizar, o tecido foi retirado da panela, lavado e estendido para secagem à sombra.

\footnotetext{
${ }^{8}$ https://www.dicio.com.br/curcuma/
} 
Figura 02: Resultado tingimento

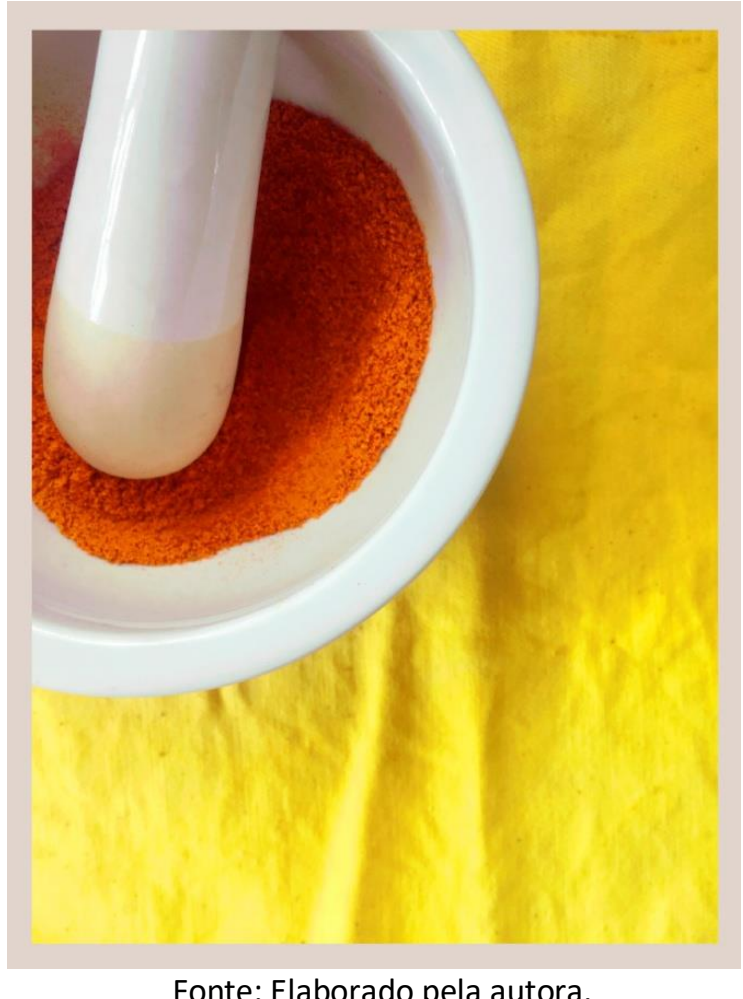

Na Figura 02, é possível observar o pigmento da cúrcuma ao lado do tecido já tingido. $\mathrm{O}$ resultado é surpreendente, o qual apresenta bastante uniformidade e vivacidade de cor. Após o tingimento, a sarja de algodão orgânico tingida foi submetida às estampas com carimbos naturais.

\subsection{Tratamento artesanal de superfície: Carimbos com elementos naturais}

Com base nos estudos realizados sobre a cultura Boruca, entende-se que a tribo valoriza demasiadamente a natureza e conecta isso com seu artesanato. A técnica de carimbo com elemento natural surge com a ideia de conexão da natureza e o design. Goode (2013) comenta que a Índia teve grande importância no desenvolvimento da estamparia em bloco ou carimbo de madeira e continua em constante evolução, produzindo modelos sofisticados (NEIRA, 2012).

O carimbo costuma ser feito de madeira, porém existem outras maneiras de executar a técnica, uma delas é através do uso de carimbos de elementos naturais. Para esta pesquisa, o início do processo se deu a partir da busca do elemento natural. Escolheu-se a planta Estrelítzia que tem referência com o tema desta coleção. Neste processo é importante que o elemento tenha uma certa rugosidade para que essa possa ser transferida para o suporte desejado. $\mathrm{Na}$ Figura 03 (A) é possível observar a planta em seu habitat natural, e em (B), uma única folha, onde é possível perceber a rugosidade que foi transferida para a o tecido. 
Figura 03: Elemento natural: Estrelítzia.

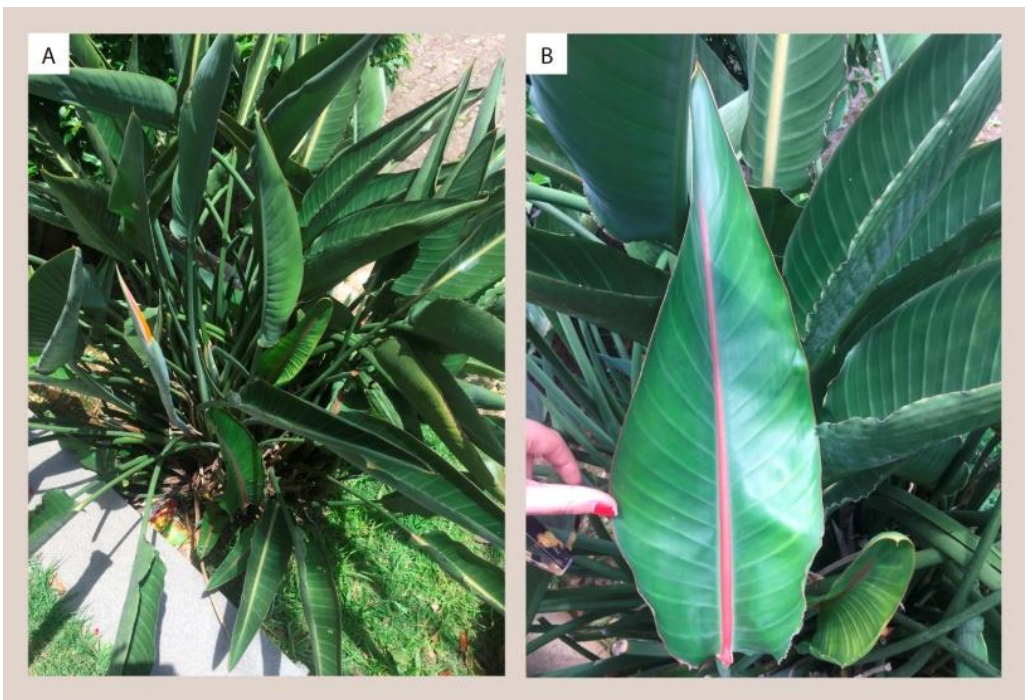

Fonte: Fotografado e elaborado pela autora.

Após a escolha do elemento, iniciou-se os ensaios. Primeiramente os testes foram realizados em folhas de papel Canson $140 \mathrm{~g} / \mathrm{m}^{2}$ formato $A 3$, e após aplicados no tecido já tingido. Utilizou-se tinta para tecido, esponja, pincel e substratos para realizar a impressão. 0 processo necessitou de precisão e cuidado, pois o excesso de tinta, assim como a escassez da mesma, não geraram um bom resultado. A Figura 04 apresenta algumas aplicações, em (A) no papel e em (B) no tecido tingido.

Figura 04: Carimbos da planta Estrelítzia em suportes variados. Em (A) no papel. Em (B) no tecido.

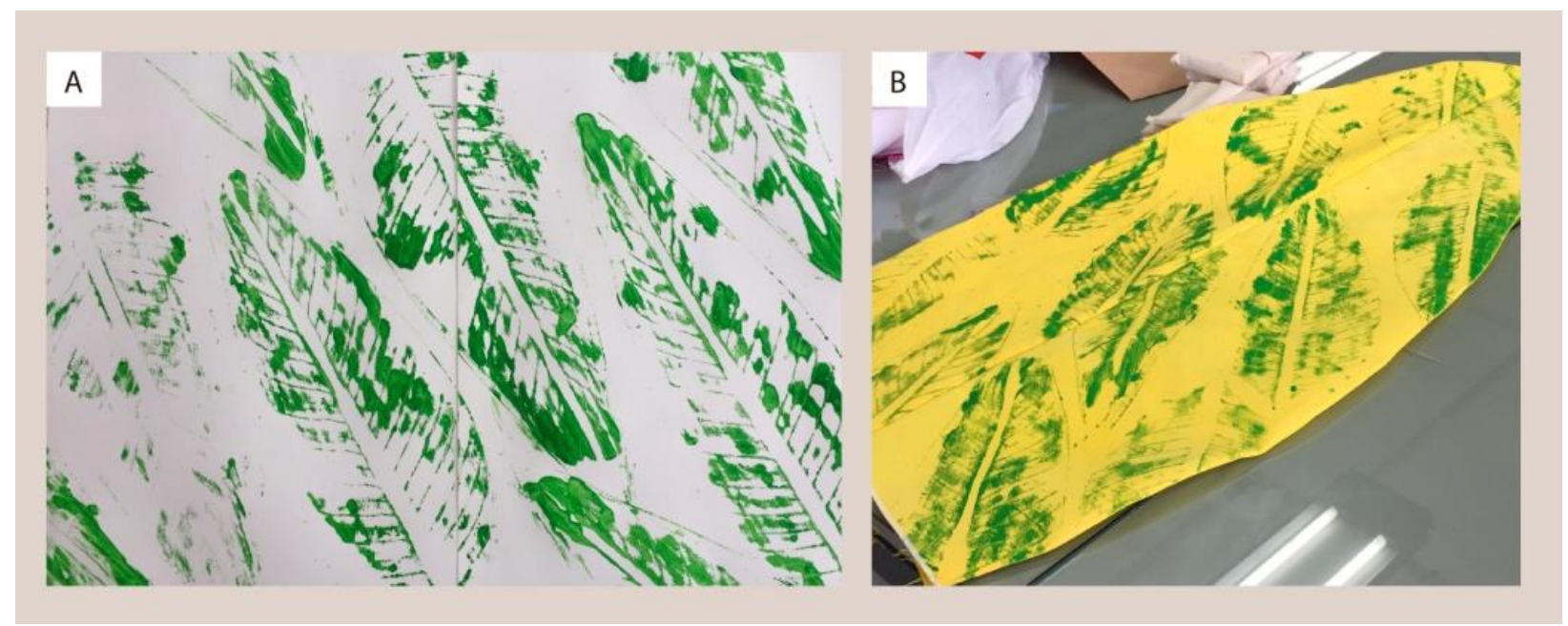

Fonte: Elaborado pela autora.

O resultado da estampa nomeada como "estampa carimbo natural" foi bastante imprevisível e proporcionou uma estética totalmente artesanal. Percebeu-se que o método promoveu uma singularidade as peças, uma vez que o mesmo carimbo nunca fica idêntico a outro, fazendo com que a estampa seja sempre irregular e exclusiva. 


\subsection{Tratamento artesanal de superfície: Bordado}

Ao tratar da tridimensionalidade das superfícies, Rubim (2013), comenta que os tricôs, as malhas e os bordados são projetos de design de superfície que apresentam texturas físicas e táteis. A autora acredita que estas superfícies têxteis por nos remeterem a tempos ancestrais nos transmitem encantamento e fascínio. A autora ainda analisa a questão do bordado: "É interessante observar como os bordados ainda são pouco explorados em soluções mais contemporâneas. Entendemos que podem ser melhor aproveitados caso sejam vistos de uma maneira nova e surpreendente" (RUBIM, 2013, p. 66).

Os desenhos bordados nas peças desta coleção de moda foram inspirados nos elementos da natureza local da tribo Boruca. A Figura 05 apresenta alguns dos elementos escolhidos, onde (A), têm-se a representação da floresta, em (B) e (C), das flores tropicais, características da Costa Rica e em (D), a asa da arara vermelha, ave muito presente no país.

Figura 05: Inspiração de bordados: em (A), representação da floresta, em (B) e (C), flores tropicais, em (D), a asa da arara vermelha

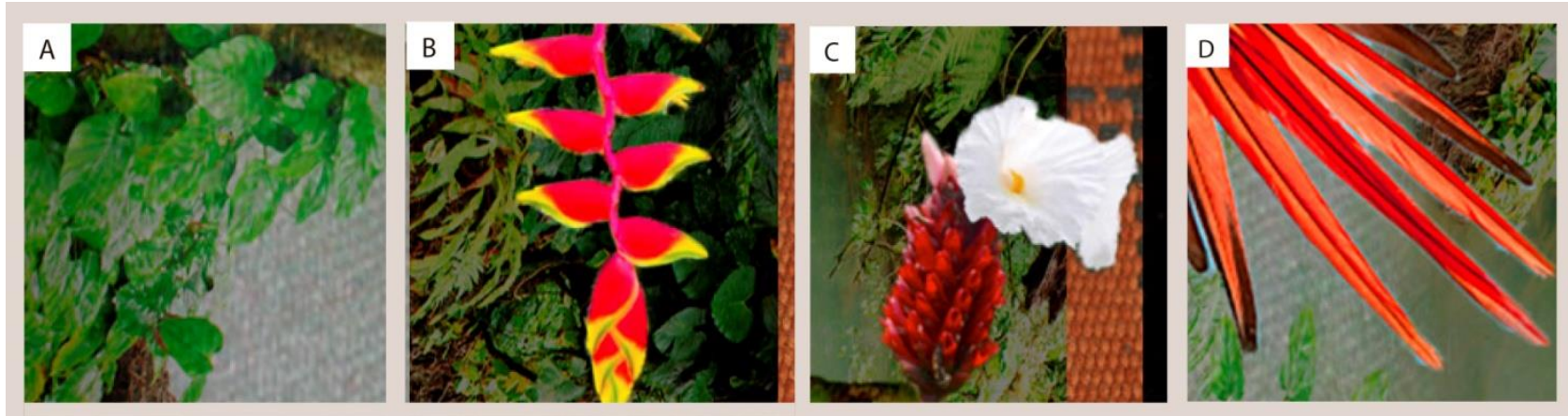

Fonte: Elaborado pela autora.

O bordado feito nesta coleção foi construído através do ponto matiz, ponto cheio, ponto atrás, ponto corrente e pesponto. As linhas utilizadas foram linhas $100 \%$ viscose e $100 \%$ algodão. A Figura 06 apresenta as etapas deste processo. Em algumas peças foi necessário o uso de uma entretela solúvel para fixar o risco do bordado. No restante, foi utilizada apenas a transferência com papel carbono diretamente no tecido.

Na Figura 06 (A) é possível, identificar o desenho do bordado sendo transferido para a entretela solúvel, em (B), tem-se a produção do bordado, em ponto matiz e percebe-se também o ponto corrente, no caule da planta. Já em (C), é apresentado um dos bordados, identificando o ponto cheio $^{9}$ (flores vermelhas e folhas grossas), pesponto ${ }^{10}$ (caule e galhos) e ponto matiz ${ }^{11}$ (flores laranjas). Em (D), percebe-se a construção de um bordado, todo em ponto matiz.

\footnotetext{
${ }^{9}$ Ponto Cheio: Ponto básico popular de preenchimento.

${ }_{10}$ Pesponto: Ponto de contorno

${ }^{11}$ Ponto Matiz: Pontos alternados entre curtos e longos.
} 


\section{Artigo Completo}

Figura 06: Processo de bordado
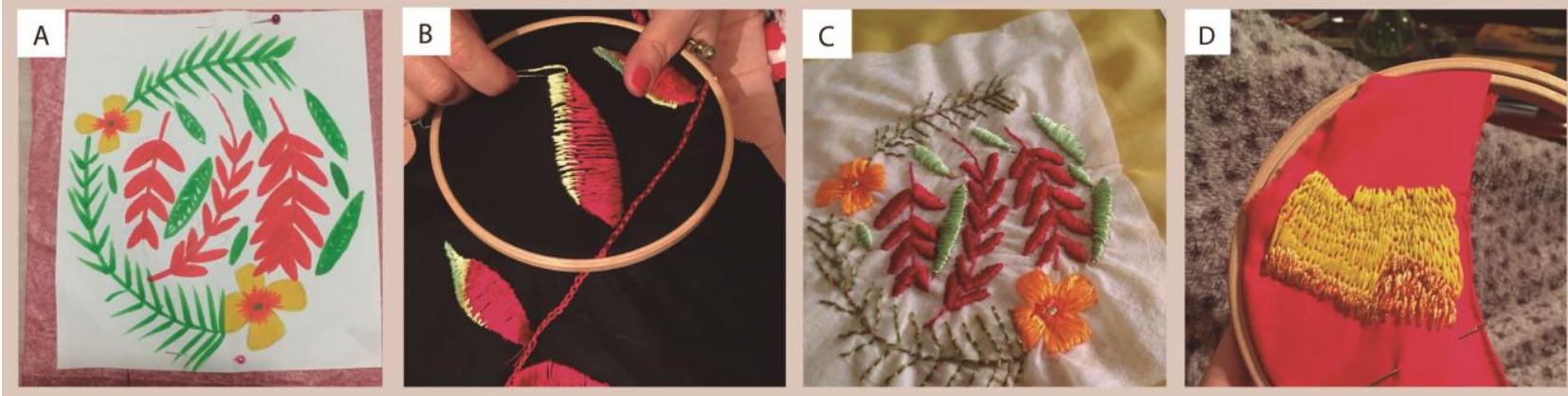

Fonte: Fotografado e elaborado pela autora.

Com o resultado deste processo, percebeu-se que para bordar elementos naturais e ter uma representação realista, principalmente de flores ou pássaros que possuem gradiente de cores, é relevante o uso do ponto matiz. Além disto, as linhas de viscose com as linhas de algodão trouxeram um brilho singular às peças.

\subsection{Aplicação das estampas na coleção de moda}

A coleção Baile de los Diablitos foi o resultado de diversas técnicas manuais de tratamento de superfície têxtil aliadas ao design de moda inspiradas nos Borucas e na natureza que os cerca. Através dos resultados obtidos, pode-se perceber o diferencial que o tratamento artesanal de superfície pode proporcionar.

Figura 07: Resultados das aplicações do tratamento artesanal de superfície na coleção de moca conceitual.

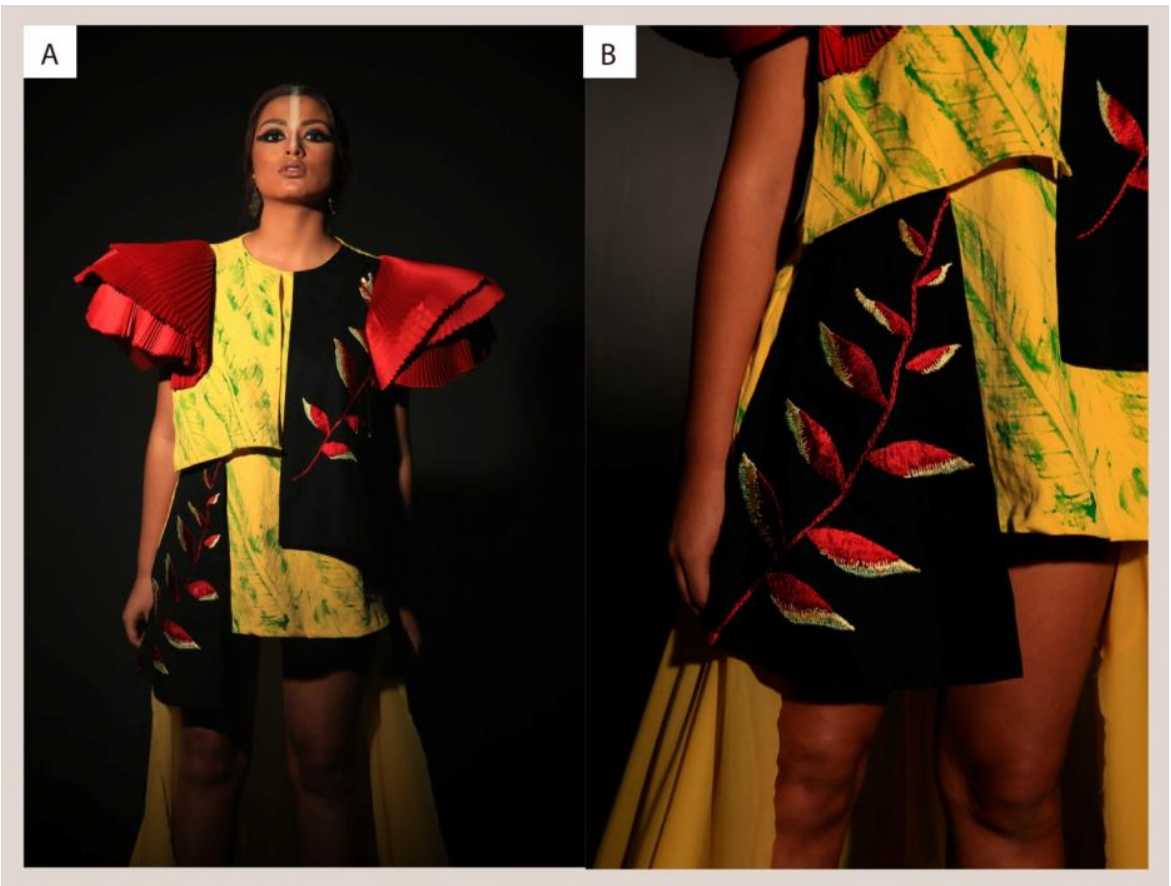

Fonte: Elaborado pela autora. 
Na Figura 07 (A), mostra a foto da coleção, ou seja, aquela que leva os conceitos estudados e abordados, e em (B), nota-se os detalhes dos processos explorados, como o tingimento natural, a estamparia através de carimbos de elementos naturais e o bordado manual.

\section{CONCLUSÃO}

Durante todo o estudo, percebeu-se que os Borucas possuem um artesanato bastante original, rico em formas. Notou-se que a tribo possui uma intensa relação com os trabalhos manuais. Os elementos como máscaras e natureza local, foram as principais fontes de inspiração para a construção das superfícies têxteis. Suas formas e figuras se transformaram em bordados e estampas. Os tecidos passaram pelo processo de tingimento natural. Durante todo este processo, percebeu-se que o trabalho manual possui uma relação afetiva com as peças, contando histórias através das mesmas.

O trabalho manual aplicado gerou exclusividade e originalidade, além disto, por serem feitas à mão, carregam carinho e afeto. Este trabalho proporcionou conhecimento de uma cultura totalmente distinta e única, o qual gerou uma grande admiração pela tribo estudada. Acredita-se que este projeto traz uma contribuição para o design e a moda, tanto no meio profissional como acadêmico, ao resgatar e apresentar processos manuais e artesanais aplicados a uma coleção de moda conceitual.

\section{REFERÊNCIAS}

BORUCA.ORG. Site institucional. 2017. Disponível em: <http://boruca.org/>. Acesso em: 19 abr. 2017.

BUENO, Ricardo. Alma Brasileira. Rio de Janeiro: Quatro Projetos, 2014.

CHAVES, Alejandra Guevar; INCERA, Denis. El baile de los diablitos en Boruca: Magia vs Dominación. Revista Herencia, v. 28, n. 2, p. 65-80, 2015.

ETNOBOTÂNICA. Disponível em: < http://www.etno-botanica.com/> Acesso em: 01 jan. 2017.

FERREIRA, Luis Gustavo; NOGUEIRA, Natália; GRACIANE Fernanda. Corantes naturais e sustentabilidade no setor têxtil. Fórum ambiental da alta paulista, [S.L], v. 9 n.1, 2013.

FLETCHER, Kate. GROSE, Lynda. Moda \& sustentabilidade: design para mudança. São Paulo: Senac São Paulo, 2011.

FREITAS, Renata Oliveira Teixeira de. Design de superfície: as ações comunicacionais táteis nos processos de criação. São Paulo: Blucher, 2012.

GOODE, Amanda Briggs. Design de estamparia têxtil. São Paulo: Bookman, 2014.

LIMA, Ricardo. Artesanato: cinco pontos para discussão. IPHAN, 2005. Disponível em: http://portal.iphan.gov.br/uploads/publicacao/Artesanato_Cinco_Pontos_para_Discussao.pdf

NEIRA, Luz Garcia. Impressão digital, estética artesanal. Revista Redige, v. 3, n. 1, abr. 2012, p. 18- 
31. Disponível em: <www.cetiqt.senai.br/redige>. Acesso em: 15 abr. 2017.

PACHECO, Miguel Angel Quesada. Narraciones Borucas. Costa Rica: Editorial de La Universidad de Costa Rica, 1996.

PÉREZ, Pedro Vargas. Dos festividades borucas: el baile de los diablitos y la fiesta de los negritos. Inter Sedes, v. 6, n. 11, p. 137-143, 2005.

RUBIM, Renata. Desenhando a superfície: textos design. 3. ed. Porto Alegre: Rosari, 2013.

RUTHSCHILLING, Evelise. Design de superfície. Porto Alegre: UFRGS, 2008.

TEIXEIRA, Juliana Lima. Design de superfície: taxionomia e práticas de projeto em escolas de design em Curitiba, PR. 2013. Dissertação (Mestrado em Design) - Departamento de Design, Setor de Artes, Comunicação e Design, Universidade Federal do Paraná, Curitiba, 2013. 